ARTIGO ORIGINAL

\title{
É economicamente viável o plantio de araucária? Uma análise entre a espécie e seu principal substituto, o pinus
}

\author{
Are araucaria plantations economically viable? An analysis against its main \\ substitute: pine

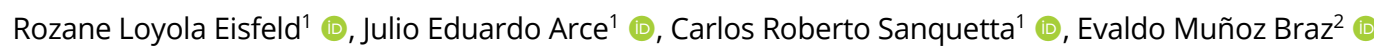 \\ 'Universidade Federal do Paraná - UFPR, Curitiba, PR, Brasil \\ ²Empresa Brasileira de Pesquisa Agropecuária - Embrapa Florestas, Colombo, PR, Brasil
}

Como citar: Eisfeld, R. L., Arce, J. E., Sanquetta, C. R., \& Braz, E. M. (2020). É economicamente viável o plantio de araucária? uma análise entre a espécie e seu principal substituto, o pinus. Scientia Forestalis, 48(128), e3408. https://doi.org/10.18671/scifor.v48n128.18

\begin{abstract}
Resumo
A araucária (Araucaria angustifolia (Bert.) O. Kuntze), embora tenha tido importante papel na economia madeireira do estado do Paraná no século XX, vem perdendo gradativamente sua área de ocorrência natural e de plantio. $O$ presente trabalho tem por objetivo realizar uma análise comparativa de viabilidade econômica entre plantios de A. angustifolia e Pinus taeda, objetivando-se a produção madeireira. Para tanto, foram utilizados indicadores econômicos como VPL, TIR e ROI, com base em dados de custos junto a produtores regionais e preços de madeira divulgados no Boletim de Preços de Produtos Florestais do Departamento de Economia Rural da Secretaria de Agricultura do Estado do Paraná. Ademais, buscou-se articular, de maneira histórica e legislativa, os motivos que tornam o pinus preferível, do ponto de vista produtivo, em relação à araucária. Nos resultados observa-se que a araucária poderá competir com o pinus em sítios médios, com valores superiores a 19 metros (idade índice de 15 anos). De um ponto de vista legislativo, não há impedimento legal para a utilização madeireira dos plantios de araucária. Entretanto, vê-se um sistema burocrático bastante complexo que parece ter um efeito negativo na possibilidade de utilização econômica da espécie. Os principais beneficiados por um sistema burocrático simplificado para o plantio e manejo da araucária seriam os pequenos produtores, os quais representam $90 \%$ das propriedades rurais no estado do Paraná.
\end{abstract}

Palavras-chave: Viabilidade econômica; Araucaria angustifólia; Legislação; Produção madeireira.

\begin{abstract}
Araucária (Araucaria angustifolia (Bert.) O. Kuntze), despite its importance in the economy of wood in Paraná State in the last century, has been subjected to increasing reduction in its natural and planted areas. The present work aims at comparing the economic viability for wood production between plantations of $A$. angustifolia and Pinus taeda. To do so, economic indicators such as NVP, IRR and ROI, were computed based on costs obtained from regional workers and wood prices from the Department of Rural Economy. Furthermore, the historical and legislative reasons why Pinus plantations seem to be preferable to Araucaria plantations are examined. The results show that araucaria plantations are competitive on medium sites, with more than 19 meters (age index at 15 years). From a legislative point of view, there is no federal norm that forbids the use of wood from araucaria plantations. However, a large bureaucratic system is perceived, which seems to have a negative effect on the decision for economic use of araucaria products. The main group which could benefit from a simplified system to Araucaria management is that of small rural workers, who represents $90 \%$ of small properties in the state of Paraná.
\end{abstract}

Keywords: Economic viability; Araucaria angustifolia; Legislation; Wood production.

Fonte de financiamento: Nenhuma.

Conflito de interesse: Nada a declarar.

Autor correspondente: rozaneloyolaeisfeld@hotmail.com

Recebido: 17 junho 2019.

Aceito: 22 outubro 2019.

Editor: Paulo Henrique Müller Silva.

(c) Este é um artigo publicado em acesso aberto (Open Access) sob a licença Creative Commons Attribution, que permite uso, distribuição e Br reprodução em qualquer meio, sem restrições desde que o trabalho original seja corretamente citado. 


\section{INTRODUÇÃO}

A história da araucária (Araucaria angustifolia(Bert.) O. Kuntze) está intimamente relacionada ao desenvolvimento econômico do estado do Paraná. A ampla exploração da espécie nos séculos XIX e XX, para fins econômicos, levou a uma redução significativa na sua área de ocorrência natural, passando de mais de sete milhões de hectares para menos de três milhões, com apenas 66 mil hectares pertencentes às florestas em estágio avançado de sucessão (Maack, 1968; Fundação de Pesquisas Florestais do Paraná, 2001). Estudos mais recentes, entretanto, indicam área remanescente inferior, da ordem de 2,14 milhões (Instituto de Estudos Socioambientais do Sul da Bahia, 2007) e 1,87 milhão de hectares (Accioly, 2013).

Dados oficiais foram divulgados pelo Serviço Florestal Brasileiro (SFB) por meio do Relatório do Inventário Florestal Nacional realizado no Paraná (Serviço Florestal Brasileiro, 2018). Baseado nas Imagens SPOT de 2005, concluiu-se que a cobertura de florestas naturais do Paraná é de aproximadamente 5,8 milhões de hectares, o que equivale a $29 \%$ do território do estado. A floresta ombrófila mista, área de ocorrência natural da araucária, possui atualmente 2,7 milhões de hectares. Considerando sua área original de 8,3 milhões de hectares (Fundação de Pesquisas Florestais do Paraná, 2001), isto equivaleria $32,5 \%$ da área original.

A elevada redução da área de ocorrência da espécie, catalisada por sua exploração madeireira, a levou à classificação de espécie vulnerável (Brasil, 1992) e, na última Lista Nacional Oficial de Espécies da Flora Ameaçadas de Extinção, publicada em 2014, a araucária ainda figura como essência ameaçada (Brasil, 2014). Embora o amplo espectro de portarias, resoluções, leis e instrumentos de fiscalização, em âmbitos federal e estadual, tenha sido eficaz para combater a exploração da espécie e manter as áreas remanescentes conservadas, evidentemente não se observa um aumento na sua área de ocorrência.

Dentro de uma perspectiva econômica está claro que o contexto é adverso no que concerne à utilização da madeira de araucária. O quadro legislativo que emergiu como resposta à taxa de redução da área de ocorrência natural da espécie tem um impacto, também, no setor produtivo, o qual encontra elevadas restrições e sistemas burocráticos que dificultam o processo de reflorestamento para fins comerciais da espécie (Danner et al., 2012). Além disso, espécies exóticas, como Pinus spp. e Eucalyptus spp., representam uma relevante fonte de competição mercadológica (Hoppe \& Caldeira, 2003; Santos \& Nogueira, 2007) e, em particular, no estado do Paraná, abrangem a quase totalidade de reflorestamentos para fins comerciais (Eisfeld \& Nascimento, 2015).

Atualmente, no estado do Paraná, não se observam políticas públicas que incentivem o plantio de espécies nativas para fins comerciais. Em 2013, a Secretaria do Meio Ambiente e Recursos Hídricos (SEMA) criou um grupo chamado GT araucária, responsável por elaborar uma resolução que incentive o plantio e utilização sustentável da espécie. Assim, ao admitir-se a importância dos plantios, seja por meio de monoculturas ou enriquecimento de áreas naturais, para expansão da área de ocorrência da espécie e redução do quadro de ameaça, o atual cenário tem características negativas.

De acordo com a pesquisa realizada pelo Banco Regional de Desenvolvimento do Extremo Sul (BRDE), embora a madeira da araucária seja considerada de maior qualidade em relação à madeira do pinus, este é preferível pelo mercado por não apresentar risco de conflito com legislações ambientais (Aquino, 2005) e pela perspectiva de um retorno econômico superior. Mas, economicamente, é possível a araucária competir com o pinus?

Nesse contexto, o presente trabalho tem como principal objetivo: i) comparar as perspectivas econômicas da A. angustifolia e Pinus taeda, em reflorestamentos comerciais e, ii) articular os motivos, históricos e legislativos, que caracterizam o plantio de pinus como preferível em relação ao plantio de araucária. 


\section{MATERIAL E MÉTODOS}

\section{Viabilidade econômica}

O desempenho econômico de plantios com araucária foi comparado com a sua principal cultura concorrente, o pinus. Para tanto, foi elaborado um fluxo de caixa descontado, para as duas espécies, considerando as premissas discorridas neste trabalho.

As simulações de crescimento foram desenvolvidas nos softwares Sis Pinus Taeda e Sis Araucaria (Oliveira et al., 1989; Oliveira \& Bernett, 2003), considerando índices de sítio de 21 metros e 15 metros, para pinus e araucária respectivamente, com idade índice de 15 anos. Esses valores são padrões (default) dos softwares, como representativos de um sítio médio para as espécies (Oliveira, 2011). Adicionalmente, elaborou-se cenários de aumento de sítio de dois em dois metros para a araucária, partindo-se de $15 \mathrm{~m}$ até $21 \mathrm{~m}$.

No presente estudo foi considerado um horizonte de planejamento de 20 anos, desde o plantio até a projeção do corte raso, ao fim do ciclo. Para o plantio foi prescrito um espaçamento de $3 \times 3$ metros, totalizando 1.111 árvores por hectare. Na simulação foram previstos dois desbastes, sendo o primeiro desbaste seletivo, aos 8 anos, com a retirada da quinta linha, e outro seletivo aos 16 anos, deixando 400 árvores remanescentes.

Os dados de preço da madeira foram obtidos a partir do Boletim de Preços de Produtos Florestais do Departamento de Economia Rural (DERAL), órgão vinculado à Secretaria de Estado da Agricultura e do Abastecimento do Estado do Paraná (SEAB) (Paraná, 2019), formulário anual de maio de 2018. Foi considerado o preço da madeira em $\mathrm{R} \$ / \mathrm{m}^{3}$.

O fluxo de caixa foi estruturado com dados de custos, por atividade silvicultural, praticados por produtores regionais, nas áreas de pinus. Os dados foram obtidos por meio de notas ficais de compra, consulta em lojas de varejo e a profissionais que atuam no setor de agronegócios. Como custo de terra, considerou-se um preço médio estadual de $\mathrm{R} \$ 6.000 / \mathrm{ha}$, um aproveitamento médio de $45 \%$ e uma taxa anual de arrendamento de 3,5\%. Assim, por meio da divisão do preço de terra pelo aproveitamento e taxa de arrendamento, empregou-se $\mathrm{R} \$ 467 / \mathrm{hr}$ como custo de terra. Como custo indireto (administrativo), considerou-se um valor padrão de $\mathrm{R} \$ 200 /$ ha bastante usual em valoração de ativos no estado do Paraná.

O modelo adotado para determinar a Taxa Mínima de Atratividade (TMA) é o Capital Asset Pricing Model (CAPM), ou custo do capital próprio. O custo do capital próprio é estimado observando o retorno obtido por investidores no mercado, assumindo que um investidor requer, no mínimo, o retorno oferecido por títulos considerados sem risco, acrescido do excedente de risco do investimento. O cálculo do CAPM pode ser obtido por meio da Expressão 1:

$R e=\frac{\left(R f+\left(\beta^{*} P m\right)+P p+R r\right)}{r}$

Onde: $R e$ : retorno exigido pelo capital próprio (taxa de desconto real); $R f$ : retorno obtido em títulos sem risco; $\beta$ : coeficiente para o risco geral envolvido em negócios florestais; $P m$ : prêmio de risco de mercado; $P p$ : prêmio de risco país; $R r$ : risco regional; $r$ : taxa de inflação.

Com base nessa metodologia, os seguintes valores foram considerados nessa avaliação: i) Retorno obtido em títulos livre de risco, sendo que foi adotada a taxa média para aplicações de longo prazo em títulos do tesouro Norte Americano que é igual a 2,46\% (Investing.Com, 2019); ii) Prêmio de risco de mercado, sendo que a média de retorno requerida por investidores Norte Americanos é 5,96\% (sobre os títulos livres de riscos), adotada como o prêmio de mercado para o período de 1928-2019 (Damodaran, 2019); iii) Beta: sendo adotado o índice igual a 0,63 que reflete uma média de risco para negócios florestais (Dória, 2013); iv) Prêmio pelo Risco País, que consiste num prêmio de 4,17\% com base na média de 2019do risco brasileiro (Damodaran, 2019); v) Risco Regional (Rr), adicionado como um prêmio de $1,0 \%$ à taxa base de desconto devido aos riscos de mercado 
e socioambientais; vi) Inflação, onde estimou-se o valor final da taxa de desconto em termos reais excluindo-se o efeito inflacionário da mesma. Para tanto, no presente estudo, foi utilizado uma estimativa de longo prazo para inflação Norte Americana de 2,23\% por ano (Statista, 2019).

Por fim, elaborou-se o fluxo de caixa, incidindo os custos e receitas referentes a cada espécie avaliada, tendo sido escolhidos três indicadores econômicos: Valor Presente Líquido (VPL), Taxa Interna de Retorno (TIR) e Retorno sobre o Investimento (ROI). Rezende \& Oliveira (2013) sugerem que as análises devem ser realizadas sempre utilizando mais de um indicador, já que essas ferramentas fornecem informações específicas que devem ser levadas em consideração. Ademais, tratam-se de indicadores simples de interpretar e suficientes para realizar uma discussão a respeito dos resultados econômicos encontrados.

\section{Valor Presente Líquido}

O VPL foi o principal indicador econômico analisado. Ele considera o valor de todo o fluxo de caixa descontado para o momento zero do horizonte de planejamento direcionando a decisão de investimento. Dessa forma, o resultado do VPL depende dos custos das receitas e da taxa de juros ajustada ao nível de risco do projeto, resultando em uma medida direta da atratividade econômica do investimento proposto. O VPL pode ser obtido por meio da Expressão 2.

$V P L=\sum_{j=0}^{n} R j(1+i)^{-j}-\sum_{j=0}^{n} C j(1+i)^{-j}$

Onde: $R j$ : receita do período $j ; C j$ : custo do período $j ; n$ : duração do projeto em anos; $i$ : taxa anual de juros (TMA), expressa em forma decimal.

Um VLP igual a zero indica o mínimo de recuperação do capital investido na taxa requerida.

\section{Taxa Interna de Retorno}

A TIR permite conhecer a porcentagem máxima de retorno que o projeto pode pagar pelos recursos utilizados, isto é, pode cobrir os custos do projeto. A TIR é definida por meio da Expressão 3.

$$
\sum_{j=0}^{n} R j(1+T I R)^{-j}-\sum_{j=0}^{n} C j(1+T I R)^{-j}=0
$$

\section{Retorno Sobre o Investimento (ROI)}

O ROI é um método que considera a razão entre o Lucro Antes das Taxas (EBIT) e o Capital Empregado (CAP), obtido por meio da Expressão 4.

$$
R O I=\frac{\frac{\sum_{j=1}^{n} E B I T}{n}}{\frac{\sum_{j=1}^{n} C a p}{n}}
$$

Onde: $n$ : duração do projeto em anos ou em número de períodos.

\section{Análises Históricas e Legais}

A evolução histórica da área de reflorestamentos com araucária no Brasil, considerando dados mais antigos de reflorestamentos, advém do inventário Florestal do Pinheiro no Sul do Brasil (Fundação de Pesquisas Florestais do Paraná, 1978) e, mais recentemente, dos 
relatórios anuais da IBÁ (Indústria Brasileira de Árvores), avaliado em onze períodos: 1978, 2005 a 2015.

Os dados históricos de preço de madeira de araucária foram obtidos por meio do Boletim DERAL, entre os anos de 1997 a 2018 (Paraná, 2019). Os preços correntes foram capitalizados para setembro de 2018 (valor referente à última data do preço corrente), empregando o Índice Geral de Preços do Mercado (IGP-M). A variação no período de análise, em relação aos preços, foi avaliada por meio da taxa de crescimento anual composta (CAG-R).

Quanto aos aspectos legais, o método utilizado para o estudo foi a análise diagnóstica, que consistiu no levantamento das principais leis relativas ao plantio da espécie araucária.

\section{RESULTADOS E DISCUSSÃO}

\section{Viabilidade econômica}

Na Tabela 1 são apresentados os preços de madeira em pé $\left(R \$ / \mathrm{m}^{3}\right)$, gerados conforme metodologia de amostragem estabelecida no DERAL. Preços de madeira com sortimentos inferiores a $25 \mathrm{~cm}$ não são divulgados para a araucária. Assim, adotou-se, nesta avaliação econômica, apenas os preços de pinus nos sortimentos 3 e 4 .

Tabela 1. Preços por sortimento.

\begin{tabular}{ccc}
\hline \multirow{2}{*}{ Sortimentos } & \multicolumn{3}{c}{ Preços $\left(\mathbf{R} \mathbf{/ \mathbf { m } ^ { 3 } )}\right.$} \\
\cline { 2 - 3 } & Pinus & Araucária \\
\hline $\mathrm{S} 1:>35 \mathrm{~cm}$ & $\mathrm{R} \$ 126,94$ & 250,57 \\
$\mathrm{~S} 2: 35-25 \mathrm{~cm}$ & $\mathrm{R} \$ 102,25$ & 214,43 \\
$\mathrm{~S} 3: 18-25 \mathrm{~cm}$ & $\mathrm{R} \$ 67,12$ & 67,12 \\
S4: $8-18 \mathrm{~cm}$ & $\mathrm{R} \$ 38,63$ & 38,63 \\
\hline
\end{tabular}

Fonte: Boletim Anual DERAL de maio de 2018 (Paraná, 2019).

Na Tabela 2 são apresentados os volumes retirados, em cada ano de intervenção, e a receita $(R \$ /$ ha) gerada pela comercialização da madeira.

Tabela 2. Volumes simulados e receita bruta.

\begin{tabular}{|c|c|c|c|c|c|c|c|c|c|}
\hline \multirow{2}{*}{ Gênero / Sítio } & \multirow{2}{*}{ Manejo } & \multirow{2}{*}{ Idade (anos) } & \multicolumn{5}{|c|}{ Volumes (m³/ha) } & \multirow{2}{*}{ IMA (m³/ha.ano) } & \multirow{2}{*}{$\begin{array}{l}\text { Receita } \\
\text { (R\$/ha) }\end{array}$} \\
\hline & & & VT & VS1 & VS2 & VS3 & VS4 & & \\
\hline PIN & $1 \mathrm{D}$ & 8 & 40,6 & 0,0 & 0,0 & 4,3 & 30,5 & & 1.470 \\
\hline \multirow[t]{2}{*}{ Sítio 21} & $2 \mathrm{D}$ & 16 & 199,7 & 0,0 & 39,8 & 89,5 & 57,1 & & 12.282 \\
\hline & CR & 20 & 387,2 & 8,5 & 211,1 & 110,4 & 44,9 & 31,38 & 31.807 \\
\hline ARA & $1 \mathrm{D}$ & 8 & 14,3 & 0,0 & 0,0 & 0,0 & 7,3 & & 282 \\
\hline \multirow[t]{2}{*}{ Sítio 15} & $2 \mathrm{D}$ & 16 & 66,8 & 0,0 & 0,0 & 5,3 & 52,1 & & 2.368 \\
\hline & CR & 20 & 171,5 & 0,0 & 12,8 & 109,7 & 39,4 & 12,63 & 11.630 \\
\hline ARA & $1 \mathrm{D}$ & 8 & 20,9 & 0,0 & 0,0 & 0,0 & 12,7 & & 491 \\
\hline \multirow[t]{2}{*}{ Sítio 17} & $2 \mathrm{D}$ & 16 & 94,8 & 0,0 & 0,2 & 35,3 & 52,2 & & 4.429 \\
\hline & CR & 20 & 231,9 & 0,0 & 59,0 & 117,9 & 48,7 & 17,38 & 22.426 \\
\hline ARA & $1 \mathrm{D}$ & 8 & 28,9 & 0,0 & 0,0 & 0,0 & 22,9 & & 885 \\
\hline \multirow[t]{2}{*}{ Sítio 19} & $2 \mathrm{D}$ & 16 & 125,7 & 0,0 & 2,3 & 59,1 & 53,5 & & 6.527 \\
\hline & CR & 20 & 299,6 & 0,0 & 140,1 & 103,2 & 48,5 & 22,71 & 38.842 \\
\hline ARA & $1 \mathrm{D}$ & 8 & 37,9 & 0,0 & 0,0 & 0,2 & 32,0 & & 1.250 \\
\hline \multirow[t]{2}{*}{ Sítio 21} & $2 \mathrm{D}$ & 16 & 157,6 & 0,0 & 8,4 & 90,8 & 49,8 & & 9.819 \\
\hline & CR & 20 & 373,5 & 1,1 & 222,0 & 97,9 & 45,9 & 28,45 & 56.223 \\
\hline
\end{tabular}

Fonte: Simulações Sispinus e Sisaraucária. 
Os custos variáveis são provenientes de 12 atividades envolvidas no plantio tradicional de pinus, gerando um custo total, de $\mathrm{R} \$ 4.497 /$ ha para pinus e $\mathrm{R} \$ 5.497 /$ hapara araucária, ao longo de 20 anos (Tabela 3). A diferenciação dos custos entre os dois gêneros ocorre no valor das mudas ( $R \$$ 0,34/muda de pinus e $R \$$ 1,24/muda de araucária).Dentre as atividades envolvidas, as que geram maior custo por hectare, em ordem decrescente são: aplicações de herbicidas, plantio e combate à formiga.

Tabela 3. Detalhamento dos custos da reforma de pinus e araucária.

\begin{tabular}{|c|c|c|c|c|c|}
\hline \multirow{2}{*}{$\begin{array}{l}\text { Dias } \\
\text { plantio }\end{array}$} & \multirow[b]{2}{*}{ Prescrição } & \multirow[b]{2}{*}{ Fator } & \multicolumn{3}{|c|}{ Preços (R\$/ha) } \\
\hline & & & Serviço & Insumo & $\begin{array}{c}\text { Final } \\
\text { (ponderado) }\end{array}$ \\
\hline-60 & Catação Pré-plantio & $100 \%$ & 280,0 & - & 280,0 \\
\hline-30 & Aplicação de Herbicida Pré Plantio & $100 \%$ & 440,0 & 138,9 & 578,9 \\
\hline-15 & Combate a formiga pré-plantio & $100 \%$ & 50,0 & 29,0 & 79,0 \\
\hline 0 & Plantio de mudas pinus & $100 \%$ & 562,0 & 377,7 & 939,7 \\
\hline 0 & Plantio de mudas araucária & $100 \%$ & 562,0 & 1377,6 & $1.939,6$ \\
\hline 90 & Aplicação de Herbicida Pós Plantio & $100 \%$ & 460,0 & 138,9 & 598,9 \\
\hline 120 & Combate a formiga & $100 \%$ & 50,0 & 29,0 & 79,0 \\
\hline 450 & Aplicação de Herbicida Pós Plantio & $100 \%$ & 460,0 & 310,1 & 770,1 \\
\hline 510 & Combate a formiga & $50 \%$ & 50,0 & 29,0 & 39,5 \\
\hline 600 & Roçada de Manutenção em Área Total & $25 \%$ & 430,0 & - & 107,5 \\
\hline 720 & Combate a formiga & $50 \%$ & 50,0 & 29,0 & 39,5 \\
\hline 800 & Aplicação de Herbicida Pós Plantio & $100 \%$ & 460,0 & 310,1 & 770,1 \\
\hline 880 & Roçada de Manutenção em Área Total & $50 \%$ & 430,0 & - & 215,0 \\
\hline
\end{tabular}

Cotação dólar em 11 de junho de 2019: 3,87 R\$ / U\$.

O custo da terra, conforme descrição metodológica, foi de $R \$ 467 /$ ha e o custo administrativo foi de $\mathrm{R} \$ 200 / \mathrm{ha}$. Tais custos incidem, anualmente, ao longo de todo o horizonte de planejamento e não estão obrigatoriamente relacionados com a produção. Temse, portanto, um custo fixo indireto de $\mathrm{R} \$ 667 / \mathrm{ha} / \mathrm{ano}$.

Segundo o regime de lucro presumido, há incidência de 8,78\% sob o faturamento (preço da madeira) (Tabela 4).

Tabela 4. Impostos incidentes sobre a receita bruta.

\begin{tabular}{ccc}
\hline Base & Tipo & Alíquota (\%) \\
\hline \multirow{2}{*}{ Receita } & PIS & $0,65 \%$ \\
& COFINS & $3,00 \%$ \\
& INSS RURAL & $2,05 \%$ \\
Total & IR & $3,08 \%$ \\
\hline
\end{tabular}

A TMA, calculada pelo método de Capital Asset Pricing Model, em termos reais, foi de 9,00\% ao ano (Tabela 5). 
Tabela 5. Composição da TMA.

\begin{tabular}{ccc}
\hline Item & Fonte & Valor \\
\hline Taxa Livre de Risco (10-anos TBond- Junho, 2019) & Investing.Com (2019) & $2,46 \%$ \\
Prêmio de Risco do Mercado Americano (1928 - 2019) & Damodaran (2019) & $5,96 \%$ \\
Beta Desalavancado (Setor Florestal) & Dória (2013) & 0,63 \\
Prêmio de Risco do País (últimos 5 anos) & Damodaran (2019) & $4,17 \%$ \\
Risco Regional & Autor & $1,00 \%$ \\
Taxa de Desconto Nominal & & $11,99 \%$ \\
Taxa de Inflação Projetada & Statista (2019) & $\mathbf{2 , 2 3 \%}$ \\
Taxa de Desconto Real - Após Impostos & & $\mathbf{9 , 1 4 \%}$ \\
Taxa de Desconto Real Ajustada - Após Impostos & & $\mathbf{9 , 0 0 \%}$
\end{tabular}

Nos sítios padrões, $21 \mathrm{~m}$ e $15 \mathrm{~m}$, para pinus e araucária, respectivamente, as receitas totalizaram $R \$ 45.559 /$ ha e $R \$ 14.280 /$ ha; os custos totalizaram $R \$ 18.415$ /ha e $R \$$ 19.415/ha(sem impostos). Na Tabela 6 são apresentados os indicadores econômicos VPL, TIR, ROI, para as espécies analisadas, assim como para os cenários de variação de sítio para araucária.

Tabela 6. Indicadores econômicos do pinus e araucária.

\begin{tabular}{cccccc}
\hline Gênero & Sítio $(\mathbf{m})$ & ROI(\%) & VPL & TIR (\%) & A Preço** \\
\hline Pinus & 21 & $21,31 \%$ & $-\mathrm{R} \$ 314$ & $8,77 \%$ & - \\
& 15 & $6,02 \%$ & $-\mathrm{R} \$ 9.971$ & $0,00 \%$ & $+260 \%$ \\
Araucária & 17 & $11,55 \%$ & $-\mathrm{R} \$ 6.609$ & $2,91 \%$ & $+88 \%$ \\
& 19 & $19,53 \%$ & $-\mathrm{R} \$ 1.788$ & $7,82 \%$ & $+12 \%$ \\
& 21 & $28,42 \%$ & $\mathrm{R} \$ 3.626$ & $10,91 \%$ & $-23 \%$ \\
\hline
\end{tabular}

** $\Delta$ Percentual de aumento no preço da araucária para tornar o igual ao VPL do pinus.

Os valores de VPL encontrados para este projeto, considerando os sítios padrões, foram de $\mathrm{R} \$-314 /$ ha e $\mathrm{R} \$$-9.971/ha, para pinus e araucária, respectivamente. Esses valores demonstram que o plantio de araucária, nas condições avaliadas, não foi considerado economicamente viável e possui indicadores econômicos bem inferiores aos do pinus.

Basicamente, esse resultado advém da taxa decrescimento inferior da araucária. Os cenários de aumento de sítio demonstraram resultados semelhantes ao pinus e poderiam ser alcançados se a araucária estivesse em um sítio superior a19m (idade índice de 15 anos), o que acarretaria um aumento do IMA de $12,63 \mathrm{~m}^{3} \cdot$ ha $^{-1}$.ano-1 (sítio utilizado na análise) para $22,71 \mathrm{~m}^{3}$.ha-1.ano ${ }^{-1}$. Na Figura 1 é apresentada uma comparação dos VPLs considerando as premissas ora apresentadas, assim como o cenário de aumento de sítio para araucária.

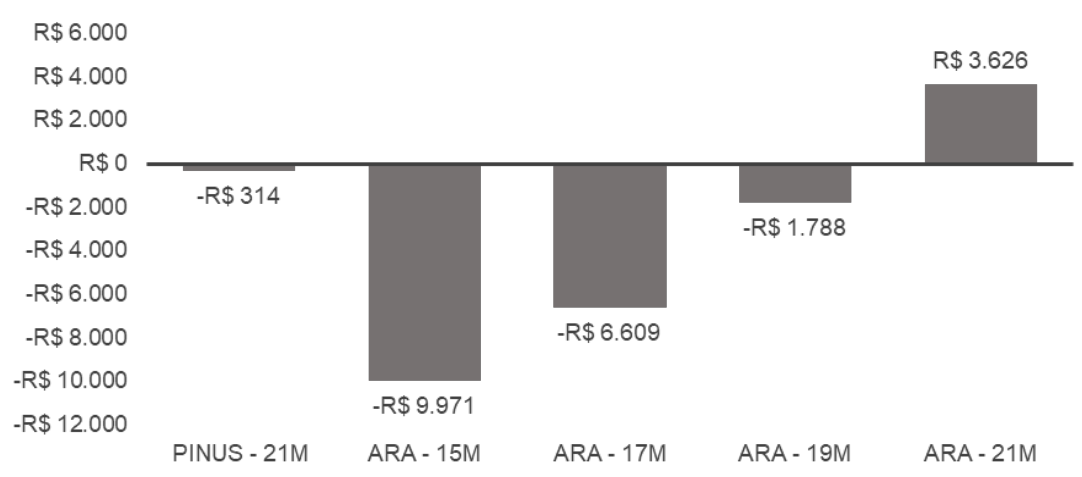

Figura 1. VPL de pinus e araucária. 
Quanto à TIR, foram obtidos valores de 8,77\% e 0,00\%, referente ao pinus e à araucária com sítios padrões, respectivamente. O aumento de sítio da araucária, para 19 metros, refletiria em uma TIR de 7,82\%. Assim, o pinus em um sítio de $21 \mathrm{~m}$ e a araucária em um sítio de $19 \mathrm{~m}$ seriam considerados investimentos ainda com risco, pois o valor da TIR é levemente inferior à taxa mínima de atratividade. No entanto, se considerarmos a araucária em um sítio de $21 \mathrm{~m}$, a viabilidade econômica torna-se evidente, configurando um projeto com maior factibilidade em relação ao pinus. Em relação aos valores de ROI, obteve-se 21,31\% e 6,02\%.

Em um cenário hipotético de aumento de preço, de modo a equalizar os indicadores econômicos entre pinus e araucária, faz-se necessário um aumento de $+12 \%$ e $+88 \%$, respectivamente, para os sítios $19 \mathrm{~m}$ e $17 \mathrm{~m}$.

Portanto, os valores dos indicadores econômicos encontrados nesta avaliação confirmam que a araucária, nos preços atuais informados pelo DERAL, é viável economicamente e pode competir com o pinus, somente em sítios acima de 19m e IMA superior a $23 \mathrm{~m}^{3} \mathrm{ha}^{-1} \mathrm{ano}^{-1}$.Deve-se salientar, no entanto, que na presente análise econômica, apenas a rentabilidade com a extração madeireira é considerada. Pode-se, entretanto, incluir no balanço econômico da espécie, a rentabilidade de seu produto não madeireiro, o pinhão. Potencialmente, nesse contexto, ter-se-ia um cenário mais positivo a partir dos 20 anos. De fato, o pinhão pode, inclusive, ser mais rentável que a própria madeira da espécie (Zanette, 2010; Danner et al., 2012).

\section{Aspectos históricos e legislativos}

A Lei Federal n 5.106 de 1966 (Brasil, 1966), responsável pela concessão de incentivos fiscais aos empreendimentos florestais, catalisou uma série de reflorestamentos no estado do Paraná, no período de 1966 a 1979. Ao todo, foram plantados 655,5 mil hectares, deixando o estado em terceiro lugar dentre os estados da União em reflorestamentos. No entanto, embora a araucária tenha tido importante papel na indústria madeireira do Paraná, no século passado, apenas $7,43 \%$ dos reflorestamentos foram contemplados com a espécie, sendo a maior parte realizada com Pinus spp (Brepohl, 1980).

Conforme Koehler (2009), a maioria dos plantios de araucária, não correspondeu às expectativas de retorno econômico, enquanto os resultados obtidos com pinus ou eucalipto eram cada vez mais promissores, induzindo a um redirecionamento dos investimentos para essas espécies exóticas. Em 2001, por exemplo, o Paraná possuía 688,4 mil hectares de florestas plantadas, onde 532,4 mil hectares correspondiam a plantações de Pinus spp., 105,6 mil hectares de Eucalyptus spp. e o restante, 50,3 mil hectares, eram compostas por outras espécies arbóreas, principalmente A. angustifolia (Santos \& Nogueira, 2007).

Atualmente observa-se uma gradativa redução nos plantios de araucária no estado do Paraná. No Sul do Brasil, tem-se uma redução de 59 mil hectares, em 1978, para 11 mil hectares, em 2017 (redução média de 1,3 mil ha por ano), como mostra a Figura 2.

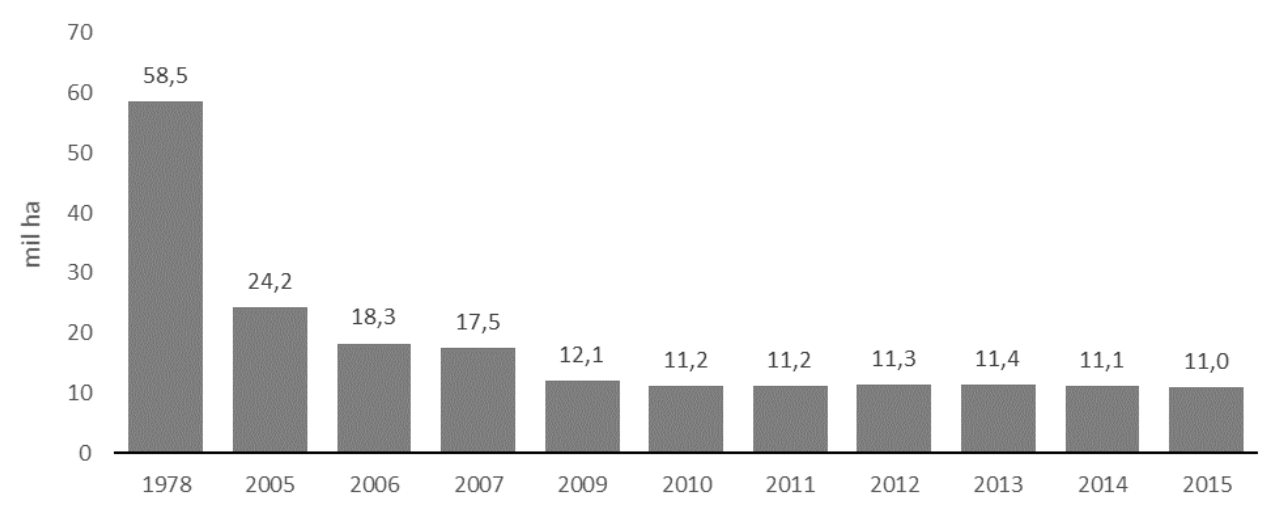

Figura 2. Área plantada com araucária no Brasil de 1978 a 2015. Fonte: FUPEF (Fundação de Pesquisas Florestais do Paraná, 1978) e Boletim Anual IBÁ (Industria Brasileira de Árvores, 2017). 
No que tange aos preços atuais da madeira no mercado, os valores históricos corrigidos sofreram pouca alteração, com CAG-R de $-0,42 \%$ para o sortimento $>35 \mathrm{~cm}$ e $+0,16 \%$ para o sortimento $<35 \mathrm{~cm}$. Entretanto, como ilustrado na Figura 3, observa-se uma redução de preço, mais acentuada, nos últimos anos. Entre 2009 a 2018, a CAG-R foi de -3,13\% para o sortimento $>35 \mathrm{~cm}$ e $-0,52 \%$ para o sortimento $<35 \mathrm{~cm}$.

\section{a. Preços Correntes}

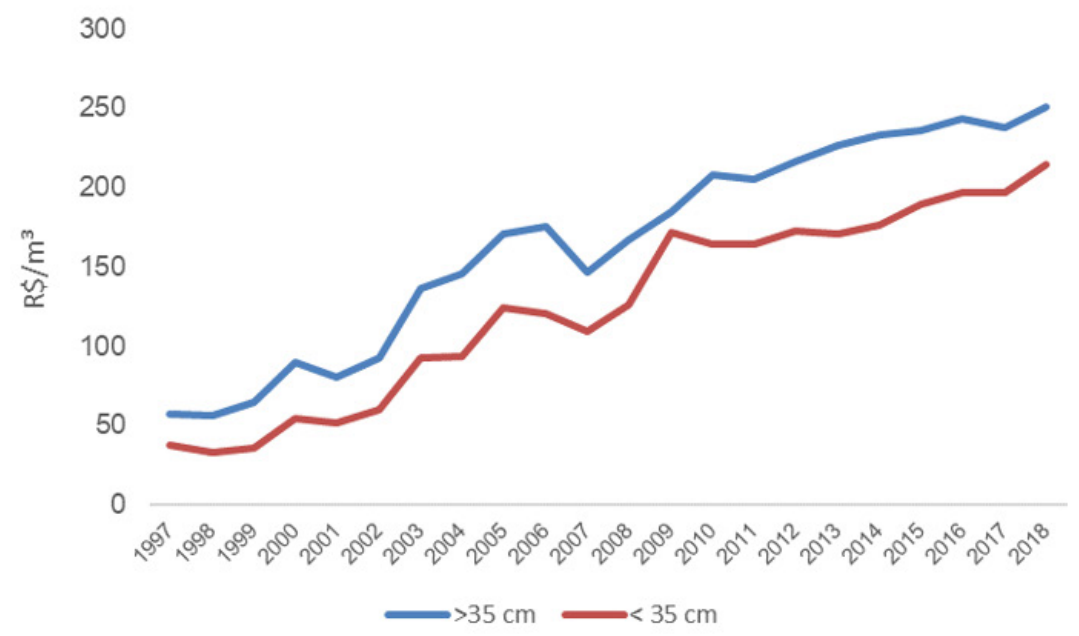

b. Preços Corrigidos

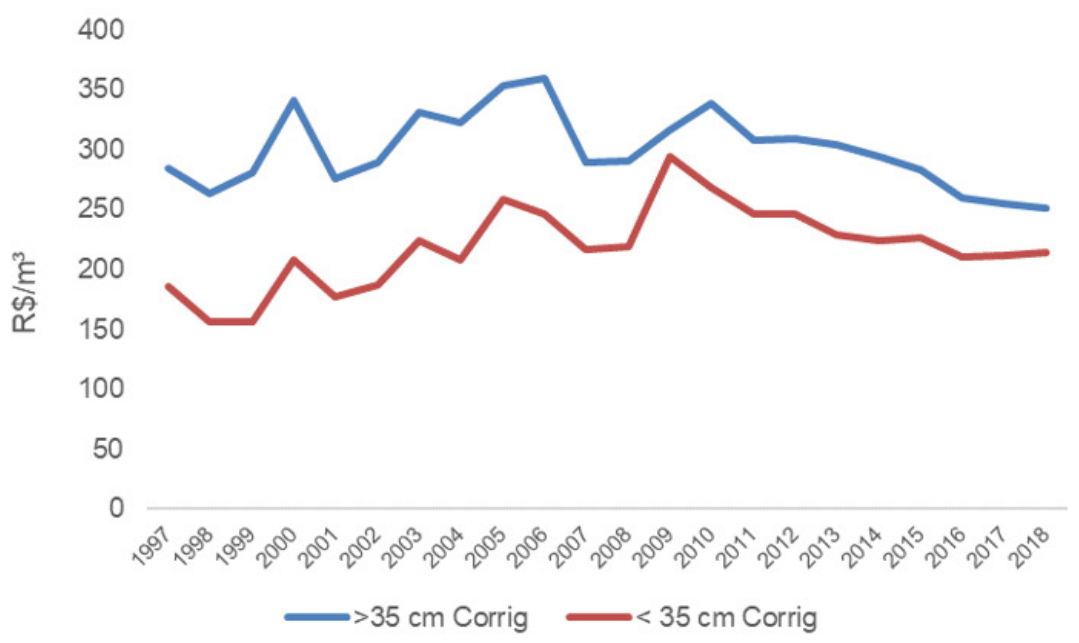

Figura 3. Preços de madeira de araucária no Paraná. Fonte: Boletim DERAL (Paraná, 2019). Preços Corrigidos IGP-M.

Danner et al. (2012) citam que a baixa representatividade da araucária em plantios florestais deve-se, possivelmente, à intensa pressão legislativa sobre o corte da espécie, reconhecida como ameaçada de extinção na flora brasileira. Ainda, Hoppe \& Caldeira (2003) relacionaram a redução na taxa de plantio dessa espécie com fatores como a exigência de sítios de boa qualidade, falta de conhecimentos sobre as procedências mais adequadas em diferentes condições edafo-climáticas, dificuldades na obtenção de algumas procedências testadas e aprovadas, falta de sementes melhoradas geneticamente, falta de conhecimentos silviculturais e nutricionais que proporcionem melhor relação produtividade/custo de produção, menor crescimento volumétrico comparado às espécies exóticas e, principalmente, a restrições normativas e legais para a preservação da espécie. 
De acordo com a Lei 12.651 de 2012 (Brasil, 2012), no artigo 35, inserido no Capítulo VIII, o plantio com araucária independe de autorização prévia devendo, apenas, ser informado ao órgão competente em um prazo de 1 (um) ano. Assim como, permite-se, independentemente de autorização prévia, o corte de espécies nativas plantadas, desde que a exploração esteja previamente declarada para fins de controle de origem. Quanto ao transporte e armazenamento, conforme o artigo $6^{\circ}$, da Lei 12.651 de 2012, é requerida licença do órgão competente do SISNAMA. A licença prevista no caput será formalizada por meio da emissão do Documento de Origem Florestal (DOF), que deverá acompanhar o material até o beneficiamento final.

O capítulo IV do Decreto 6.660 (Brasil, 2008) versa sobre o plantio e reflorestamento de espécies nativas, os quais independem de autorização do órgão ambiental competente (artigo $12^{\circ}$ ). $\mathrm{O}$ artigo 14 rege que o corte ou a exploração de espécies nativas comprovadamente plantadas somente serão permitidos se o plantio ou o reflorestamento tiver sido previamente cadastrado junto ao órgão ambiental, cumprindo o prazo máximo de 60 dias após o plantio. $O \S 1^{\circ}$ dispõe que será criado o cadastro de espécies nativas plantadas ou reflorestadas. Tal cadastro não foi criado até o presente.

No ato do corte, pelo art. 15, deve ser notificado ao órgão ambiental contendo informações do número do cadastro, volume por espécie, localização da área com coordenadas geográficas. O termo "notificação" refere a uma autorização imediata, espontânea e automática.

Assim, resumidamente, a legislação atual não veda o corte de plantios com espécies florestais ameaçadas de extinção, entretanto o proprietário terá que se responsabilizar por: i) cadastro junto ao órgão ambiental, cumprindo o prazo máximo de 60 dias após o plantio; ii) DOF para o transporte ou armazenamento. A emissão do DOF será realizada após a análise das informações prestadas pelo requerente e prévia vistoria de campo que comprove o plantio.

Pode-se afirmar que as normativas legais não proíbem o corte da araucária. No entanto, existe um sistema burocrático bastante expressivo, entre cadastramento de plantio, vistoria técnica e emissão do DOF, para que seja autorizado o corte dos plantios. Em relação a esses aspectos, as essências exóticas são totalmente beneficiadas, pela não exigência de qualquer autorização de corte.

Segundo a pesquisa conduzida pelo BRDE (Aquino, 2005), apesar da madeira da araucária ser considerada superior à do gênero pinus, atualmente o esse é preferido pelos mercados por não representar risco de conflitos com a legislação ambiental. Segundo esta fonte, as negociações de fornecimento de madeira ou de produtos derivados da araucária enfrentam sérios obstáculos, tanto no mercado interno quanto externo, por se tratar de uma árvore nativa inclusa na lista de espécies ameaçadas de extinção. Esse quadro se propaga tanto sobre os plantios monoespecíficos quanto sobre os plantios em meio às vegetações nativas.

Mas como reverter um quadro de ameaça? É certo que o plantio com finalidade econômica, é uma das formas. Entretanto, empresas de base florestal não demonstram qualquer intenção de plantios com espécies nativas (Eisfeld \& Nascimento, 2015). Ao se aceitar que não haverá novos plantios em empresas florestais, a araucária dependerá de pequenos produtores. De acordo com o Instituto de Terras, Cartografia e Geologia do Paraná (2018), pequenos produtores representam $90 \%$ das propriedades inclusas como pequenas propriedades ou minifúndios (menores que 4 módulos rurais). Esse grupo, particularmente, poderia ser beneficiado com procedimentos simplificados de manejo dentro da Reserva Legal de suas propriedades. Tal medida poderia catalisar uma expansão na prática de plantio da araucária, uma vez que haveria a garantia de utilização econômica da espécie.

\section{CONCLUSÕES}

- Indicadores econômicos tornam o plantio de araucária interessante, em relação ao pinus, em Índices de Sítio superiores aos 19m na idade 15 anos; 
- Em sítios inferiores, com $17 \mathrm{~m}$, a araucária pode ser competitiva com acréscimo médio de preço de $+88 \%$;

- Existe uma redução anual dos reflorestamentos da araucária. No Sul do Brasil, a redução foi de 58,5 mil ha em 1978 para 11 mil ha em 2015, ou seja, -1,3 mil ha por ano;

- Apesar de haver uma baixa oferta da madeira de araucária, seu preço se manteve estável ao longo dos anos. Valores corrigidos, mostraram um CAGR de $-0,42 \%$ do sortimento acima de $35 \mathrm{~cm}$ e $+0,16 \%$ no sortimento inferior a $35 \mathrm{~cm}$;

- A legislação atual não veda o corte de plantios com espécies florestais nativas, inclusive as ameaçadas de extinção;

- A burocracia para autorizar o corte é grande com exigência de cadastro junto ao órgão ambiental e expedição do DOF.

\section{REFERÊNCIAS}

Accioly, P. (2013). Mapeamento dos remanescentes vegetais arbóreos do estado do Paraná e elaboração de um sistema de informações geográficas para fins de análise ambiental do estado (Tese de doutorado). Programa de Pós-graduação em Engenharia Florestal, Universidade Federal do Paraná, Curitiba.

Aquino, F. M. (2005). Cultivo da araucaria angustifolia: análise de viabilidade econômico-financeira (53 p.). Florianópolis: Gerência de Planejamento, Banco Regional de Desenvolvimento do Extremo Sul (BRDE).

Brasil. (1966, 5 de setembro). Lei Federal nº 5.106 de 02 de setembro de 1966. Dispõe sobre os incentivos fiscais concedidos a empreendimentos florestais. Diário Oficial [da] República Federativa do Brasil, Brasília.

Brasil. Ministério do Meio Ambiente. (1992, 3 de abril). Portaria IBAMA n 37-N, de 3 de abril de 1992. Reconhece como Lista Oficial de Espécies da Flora Brasileira Ameaçadas de Extinção a relação que se apresenta. Diário Oficial [da] República Federativa do Brasil, Brasília.

Brasil. (2008). Decreto $n^{\circ}$ 6.660, de 21 de novembro de 2008. Regulamenta dispositivos da Lei $n^{\circ} 11.428$, de 22 de dezembro de 2006, que dispõe sobre a utilização e proteção da vegetação nativa do Bioma Mata Atlântica. Diário Oficial [da] República Federativa do Brasil, Brasília. Recuperado em 1 de maio de 2019, de http://www.planalto.gov.br/ccivil_03/_ato2007-2010/2008/decreto/d6660.htm

Brasil. (2012, 28 de maio). Lei Federal 12.651 de 25 de maio de 2012. Dispõe sobre a proteção da vegetação nativa; altera as Leis nos 6.938, de 31 de agosto de 1981; e dá outras providências. Diário Oficial [da] República Federativa do Brasil, Brasília.

Brasil. Ministério do Meio Ambiente. (2014). Portaria MMA no 443, de 17 de dezembro de 2014. Lista Nacional Oficial de Espécies da Flora Ameaçadas de Extinção. Diário Oficial [da] República Federativa do Brasil, Brasília.

Brepohl, D. (1980). O reflorestamento com incentivos fiscais no Estado do Paraná. Revista Floresta, 11(1), 62-66.

Damodaran, A. (2019). Implied equity risk premium update. Recuperado em 10 de junho de 2019, de http://people.stern.nyu.edu/adamodar/

Danner, M. A., Zanette, F., \& Ribeiro, J. Z. (2012). O cultivo da araucária para produção de pinhões como ferramenta para a conservação. Pesquisa Florestal Brasileira, 32(72), 441-451. http://dx.doi.org/10.4336/2012.pfb.32.72.441.

Dória, S. P. (2013). Estrutura de capital da klabin e do setor de papel e celulose: uma análise comparativa para o período 2007-12 (Trabalho de conclusão de curso). Universidade Federal do Rio de Janeiro, Rio de Janeiro.

Eisfeld, R. L., \& Nascimento, F. A. (2015). Mapeamento dos Plantios Florestais do Estado do Paraná (76 p.). Curitiba: Instituto de Florestas do Paraná.

Fundação de Pesquisas Florestais do Paraná - FUPEF. (1978). Inventário Florestal do Pinheiro no Sul do Brasil. Curitiba: FUPEF/IBDF.

Fundação de Pesquisas Florestais do Paraná - FUPEF. (2001). A Floresta com Araucária no Paraná. Conservação do Bioma Floresta com Araucária: Diagnóstico dos Remanescentes Florestais. Curitiba: FUPEF. Projeto de Conservação e Utilização Sustentável da Diversidade Biológica Brasileira PROBIO.

Hoppe, J. M., \& Caldeira, M. V. W. (2003). Correlações entre o crescimento de Araucaria angustifolia (BERTOL.) KUNTZE, plantada na Floresta Nacional de Passo Fundo, RS com as características 
químicas do solo. Revista Acadêmica Ciência Ambiental, 1(4), 33-40.

http://dx.doi.org/10.7213/cienciaanimal.v1i4.14967.

Industria Brasileira de Árvores - IBÁ. (2017). Relatório 2017. Relatório Anual (p.80). Brasília, DF: IBÁ.

Instituto de Estudos Socioambientais do Sul da Bahia - IESB. (2007). Levantamento da Cobertura Vegetal Nativa do Bioma Mata Atlântica: relatório final (84 p.). Rio de Janeiro: IESB-IGEO/UFRJ. Projeto de Conservação e Utilização Sustentável da Diversidade Biológica Brasileira - PROBIO.

Instituto de Terras, Cartografia e Geologia do Paraná. (2018). Cartografia e Geologia do Paraná - ITCG. Cadastro de Imóveis Rurais. Recuperado em 25 de maio de 2018, de http://www.itcg.pr.gov.br/modules/conteudo/conteudo.php?conteudo=8

Investing.Com. (2019). EUA a 10 anos Dados Históricos Rendimento do Título. Recuperado em 10 de junho de 2019, de https://br.investing.com/rates-bonds/u.s.-10-year-bond-yield-historical-data

Koehler, A. B. (2009). Modelagem biométrica e morfometria em povoamentos jovens de Araucaria angustifolia (Bert.) Ktze., em Tijucas do Sul, estado do Paraná (Tese de doutorado). Programa de Pósgraduação em Engenharia Florestal, Universidade Federal do Paraná, Curitiba.

Maack, R. (1968). Geografia física do Estado do Paraná. Curitiba: Editora Codepar.

Oliveira, E. B. (2011). Softwares para manejo e análise econômica de plantações florestais. Documentos, 216, 1-68.

Oliveira, E. B., \& Bernett, L. G. (2003). SisAraucaria: software para o manejo de plantações de Araucaria. In Anais do $8^{\circ}$ Congresso Florestal Brasileiro: benefícios, produtos e serviços da floresta: oportunidades e desafios do século XXI. São Paulo: Sociedade Brasileira de Silvicultura/Sociedade Brasileira de Engenheiros Florestais.

Oliveira, Y. M. M., Oliveira, E. B., \& Hafley, W. L. (1989). SisPinus: simulador de crescimento e de producao para plantios de Pinus elliottii e Pinus taeda sob manejo no sul do Brasil. In Anais do Encontro Brasileiro de Planejamento Florestal (pp. 107-118). Curitiba: EMBRAPA-CNPF.

Paraná. Secretaria de Estado da Agricultura e do Abastecimento do Estado do Paraná. Departamento de Economia Rural - DERAL. (2019). Boletim de Preços Florestais. Curitiba: Secretaria de Estado da Agricultura e do Abastecimento do Estado do Paraná. Recuperado em 10 de janeiro de 2019, de http://www.agricultura.pr.gov.br/modules/conteudo/conteudo.php?conteudo=129

Rezende, J. L. P., \& Oliveira, A. D. (2013). Análise econômica e social de projetos florestais. Viçosa: UFV.

Santos, A. J., \& Nogueira, A. (2007). Evolução da política florestal paranaense a partir da década de 90. Revista Floresta, 37(3), 419-426. http://dx.doi.org/10.5380/rf.v37i3.9938.

Serviço Florestal Brasileiro - SFB. (2018). Inventário Florestal Nacional: principais resultados: Paraná (Série Relatórios Técnicos - IFN, p. 84), Brasília: MMA.

Statista. (2019). Projected annual inflation rate in the United States from 2010 to 2024. Recuperado em 10 de junho de 2019, de https://www.statista.com/statistics/244983/projected-inflation-rate-in-theunited-states/

Zanette, F. (2010). A araucaria como fruteira para a produção de pinhões (Série Frutas Nativas, 25 p.). Jaboticabal: Funep.

Contribuição dos Autores: RLE: conceituação, curadoria de dados, análise formal, investigação, metodologia, administração do projeto, escrita - primeira redação; JEA: supervisão, validação, visualização, escrita - revisão e edição; CRS: supervisão, validação, visualização, escrita - revisão e edição; EMB: supervisão, validação, visualização, escrita - revisão e edição. 